\title{
A Case Report of Vogt's Limbal Girdle and Retinitis Pigmentosa in a Thirteen-Year-Old Boy: A Rare and Unusual Association
}

\author{
A.P. Vignesh Renuka Srinivasan Swathi Karanth Sai Vijitha \\ Department of Ophthalmology, Jawaharlal Institute of Postgraduate Medical Education \\ and Research (JIPMER), Pondicherry, India
}

\section{Key Words}

Vogt's limbal girdle $\cdot$ Retinitis pigmentosa $\cdot$ Abiotrophy

\begin{abstract}
Aim: To describe a rare case of Vogt's limbal girdle in a boy with retinitis pigmentosa. Methods: A 13-year-old boy from India presented to us with progressive diminution of vision and nyctalopia for 5 years. On examination, he had the characteristic features of retinitis pigmentosa with the fundus showing disc pallor, bony spicules and arteriolar attenuation. His anterior segment examination showed Vogt's limbal girdle in both eyes. Results: Vogt's limbal girdle is a corneal degeneration usually seen in elderly individuals. This is the first time it is seen in association with retinitis pigmentosa. It has also never been reported at such a young age. Conclusion: We report a rare case where Vogt's limbal girdle was observed in a 13year-old boy with retinitis pigmentosa. This gives further insight into the pathogenesis of the disease.

(c) 2015 S. Karger AG, Basel
\end{abstract}

\section{Introduction}

Vogt's limbal girdle is a degenerative condition of the cornea usually seen in elderly individuals; it is rarely seen under the age of 40 years. The term retinitis pigmentosa refers to a group of hereditary retinal dystrophies with characteristic retinal and electroretinographic findings in which the photoreceptors undergo progressive degeneration. The usual anterior segment associations of retinitis pigmentosa include keratoconus, posterior subcapsular

KARGER 125/s $\quad \begin{aligned} & \text { Dr. A.P. Vignesh } \\ & \text { Department of Ophthalmology, JIPMER } \\ & \text { No.12, Kamaraj Street } \\ & \text { Tagore Nagar, Pondicherry } 605006 \text { (India) } \\ & \text { E-Mail apvicky2010@ gmail.com }\end{aligned}$


Vignesh et al.: A Case Report of Vogt's Limbal Girdle and Retinitis Pigmentosa in a Thirteen-Year-Old Boy: A Rare and Unusual Association

cataract and myopia. We report this case of a rare association of Vogt's limbal girdle with retinitis pigmentosa.

\section{Case Presentation}

A 13-year-old Indian boy presented to us with progressive diminution of vision in both the eyes for 5 years. He also complained of poor vision at night. No associated systemic anomaly or syndromic association was found. His father was a diagnosed case of retinitis pigmentosa. The patient was positive for a RHO gene mutation. His vision was 20/200 in both eyes. On examination, his fundus showed typical features of retinitis pigmentosa with disc pallor, bony spicules and arteriolar attenuation (fig. 1). The findings were bilateral and symmetrical. His electroretinogram showed extinguished cone and rod responses in both the eyes (fig. 2). Visual fields were severely constricted (fig. 3). On examination of his anterior segment, we found a bilateral symmetrical crescentic white band in the interpalpebral limbus suggestive of Vogt's limbal girdle type 2 (fig. 4). He also had posterior subcapsular cataract in both eyes. Optical coherence tomography revealed a mild degree of foveal atrophy in the right eye (fig. 5). The patient's loss of vision could be attributed to the reduced photoreceptor function, cataract and foveal atrophy.

\section{Discussion}

Retinitis pigmentosa is a hereditary rod-cone dystrophy usually leading to a progressive loss of vision and night blindness. It is a kind of abiotrophy of the retina. It is associated with a number of corneal segment associations like keratoconus band-shaped keratopathy [1, 2]. Crawford [3] described a case of granular corneal dystrophy associated with retinitis pigmentosa, both contributing to vision loss. Mataftsi et al. [4] described 6 patients with retinitis pigmentosa in a sample size of 200 patients with Bietti's corneal dystrophy, and the prevalence was $3 \%$.There are also reports of corneal cloudiness and retinitis pigmentosa in mucopolysaccharidoses [5]. Hayasaka et al. [6] described a case of retinitis pigmentosa in a man's right eye, and corneal opacity, corneoiridal adhesion and normal retina in the left eye. Seneca et al. [7] described a case resembling Kearns-Sayre syndrome showing dystrophic features in the cornea and retina. Vogt's limbal girdle has rarely been associated with the disease. It is a corneal degeneration, and it is an age-related condition. It has rarely been seen in patients less than 40 years old [8]. It is a chalky white band in the interpalpebral limbus. Since the limbal girdle is a degenerative condition, the general process of abiotrophy in retinitis pigmentosa would have contributed to the development of the corneal degeneration at this age, which is usually an age-related condition. To the best of our knowledge, this is the first time Vogt's limbal girdle is associated with retinitis pigmentosa. It is also the first time it is reported at such a young age. The potential pathophysiological mechanisms causing both conditions may coexist, and thus this aspect deserves further study.

\section{Statement of Ethics}

Written informed consent was obtained from the patient and the parent for publication of this case report and any accompanying images. A copy of the written consent is available for review by the Editor of this journal. 
Vignesh et al.: A Case Report of Vogt's Limbal Girdle and Retinitis Pigmentosa in a Thirteen-Year-Old Boy: A Rare and Unusual Association

\section{Disclosure Statement}

The authors declare that there is no conflict of interest regarding the publication of this paper.

\section{References}

1 Moschos M, Droutsas D, Panagakis E, Tsioulias G, Tsalouki M: Keratoconus and tapetoretinal degeneration. Cornea 1996;15:473-476.

-2 Fishman GA, Anderson RJ, Lourenco P: Prevalence of posterior subcapsular lens opacities in patients with retinitis pigmentosa. Br J Ophthalmol 1985;69:263-266.

-3 Crawford C: Retinitis pigmentosa and granular dystrophy: a rare and unique combination in one patient. Binocul Vis Strabolog Q Simms Romano 2013;28:36-38.

4 Mataftsi A, Zografos L, Millá E, Secrétan M, Munier FL: Bietti's crystalline corneoretinal dystrophy: a crosssectional study. Retina 2004;24:416-426.

5 Cotlier E: Letter: Corneal cloudiness and retinitis pigmentosa in the mucopolysaccharidoses. N Engl J Med 1975;292:812.

6 Hayasaka S, et al: Retinitis pigmentosa in a man's right eye and corneal opacity, corneoiridal adhesion, and normal retina in the left eye. Ann Ophthalmol 2000;32:185-187.

7 Seneca S, Verhelst H, De Meirleir L, Meire F, Ceuterick-De Groote C, Lissens W, et al: A new mitochondrial point mutation in the transfer RNA(Leu) gene in a patient with a clinical phenotype resembling KearnsSayre syndrome. Arch Neurol 2001;58:1113-1118.

-8 Sugar HS, Kobernick S: The white limbus girdle of Vogt. Am J Ophthalmol 1960;50:101-107.

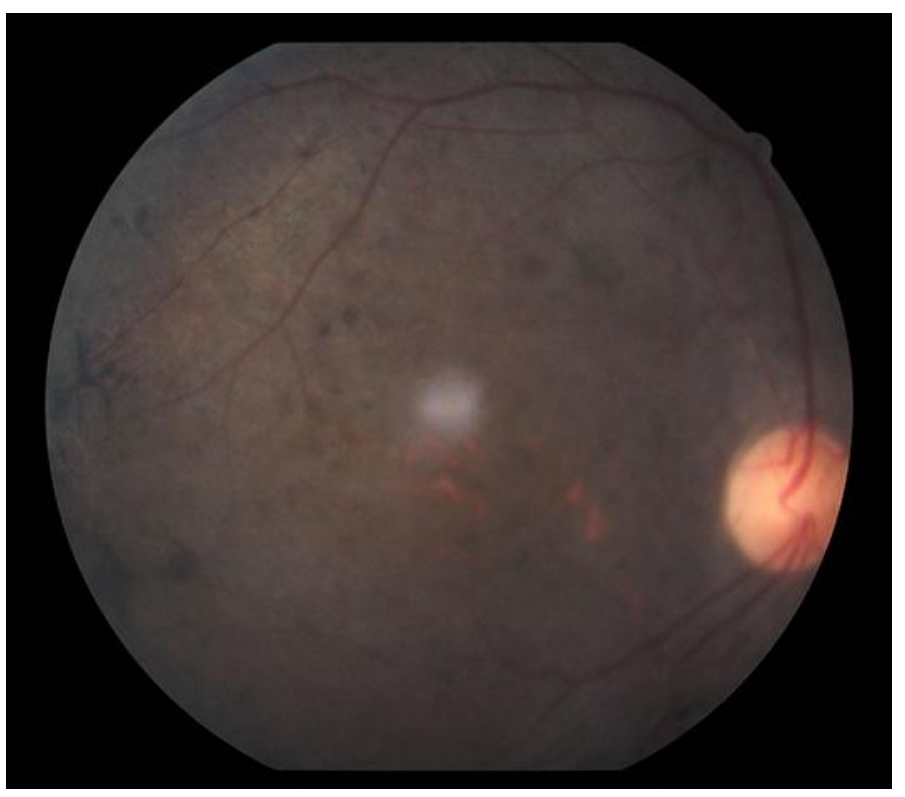

Fig. 1. Fundus photograph showing features of retinitis pigmentosa. 
Case Reports in

Ophthalmology
Case Rep Ophthalmol 2015;6:311-316

DOI: $10.1159 / 000439265$

2015 S. Karger AG, Basel www.karger.com/cop

Vignesh et al.: A Case Report of Vogt's Limbal Girdle and Retinitis Pigmentosa in a Thirteen-Year-Old Boy: A Rare and Unusual Association

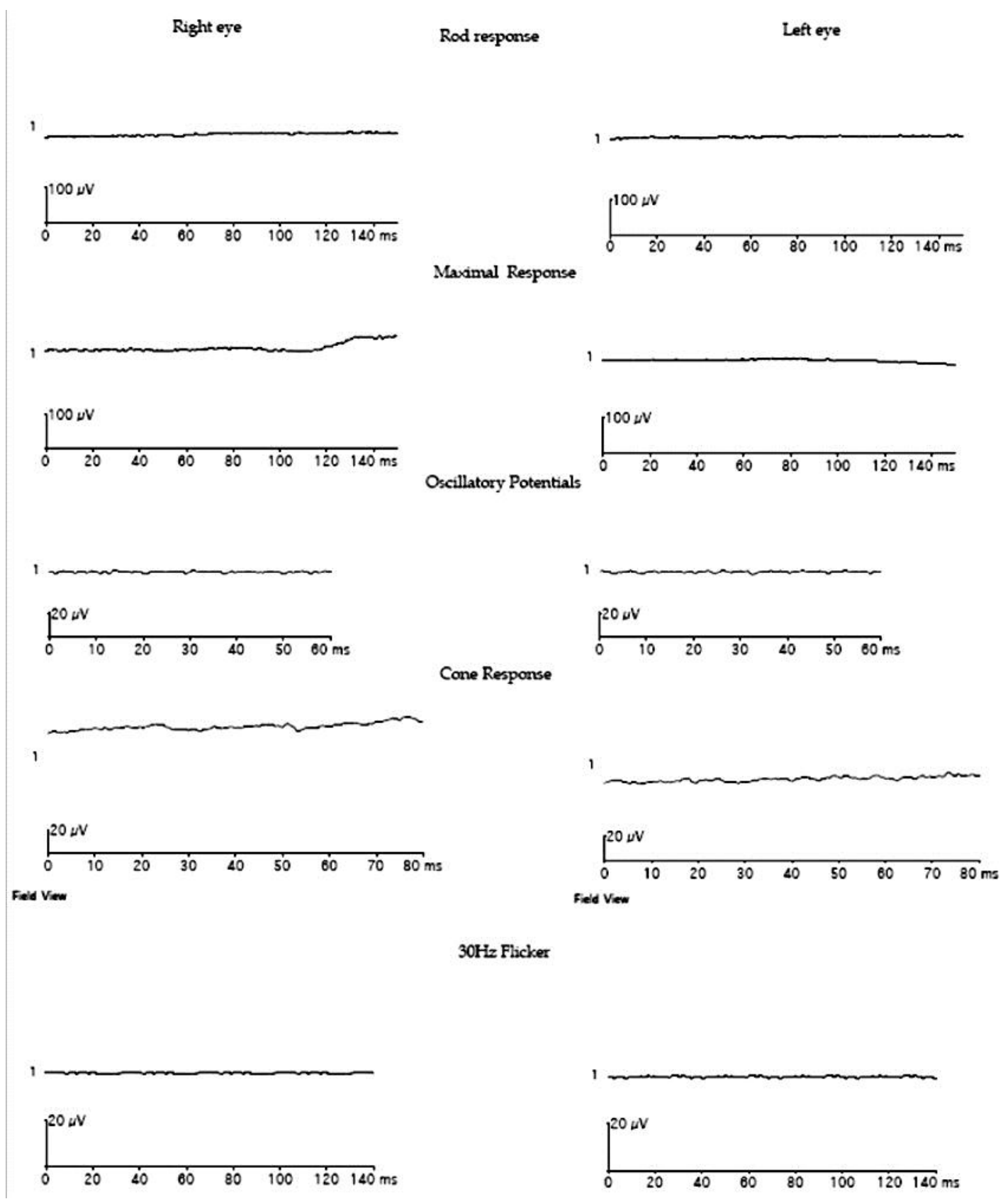

Fig. 2. Electroretinogram of the patient. 
Case Reports in

Ophthalmology

\begin{tabular}{l|l}
\hline \multicolumn{2}{l}{ Case Rep Ophthalmol 2015;6:311-316 } \\
\hline DOI: 10.1159/000439265 & $\begin{array}{l}\text { ○ 2015 S. Karger AG, Basel } \\
\text { www.karger.com/cop }\end{array}$ \\
\hline
\end{tabular}

Vignesh et al.: A Case Report of Vogt's Limbal Girdle and Retinitis Pigmentosa in a Thirteen-Year-Old Boy: A Rare and Unusual Association
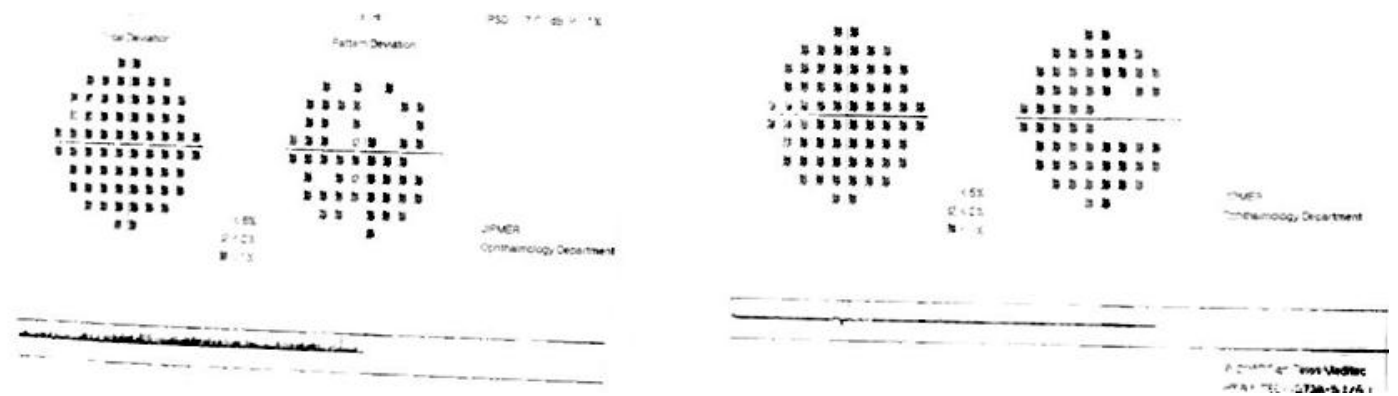

Fig. 3. Visual fields of the patient.

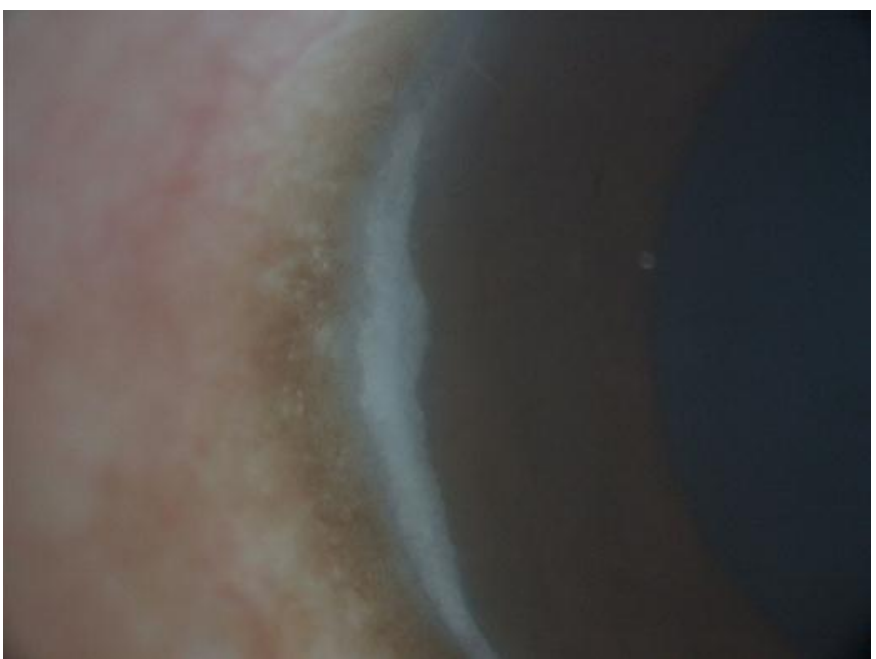

Fig. 4. Anterior segment picture showing Vogt's limbal girdle. 


\section{Case Reports in \\ Ophthalmology}

\begin{tabular}{l|l}
\hline \multicolumn{2}{l}{ Case Rep Ophthalmol 2015;6:311-316 } \\
\hline DOI: 10.1159/000439265 & $\begin{array}{l}\text { @ 2015 S. Karger AG, Basel } \\
\text { www.karger.com/cop }\end{array}$ \\
\hline
\end{tabular}

Vignesh et al:: A Case Report of Vogt's Limbal Girdle and Retinitis Pigmentosa in a Thirteen-Year-Old Boy: A Rare and Unusual Association

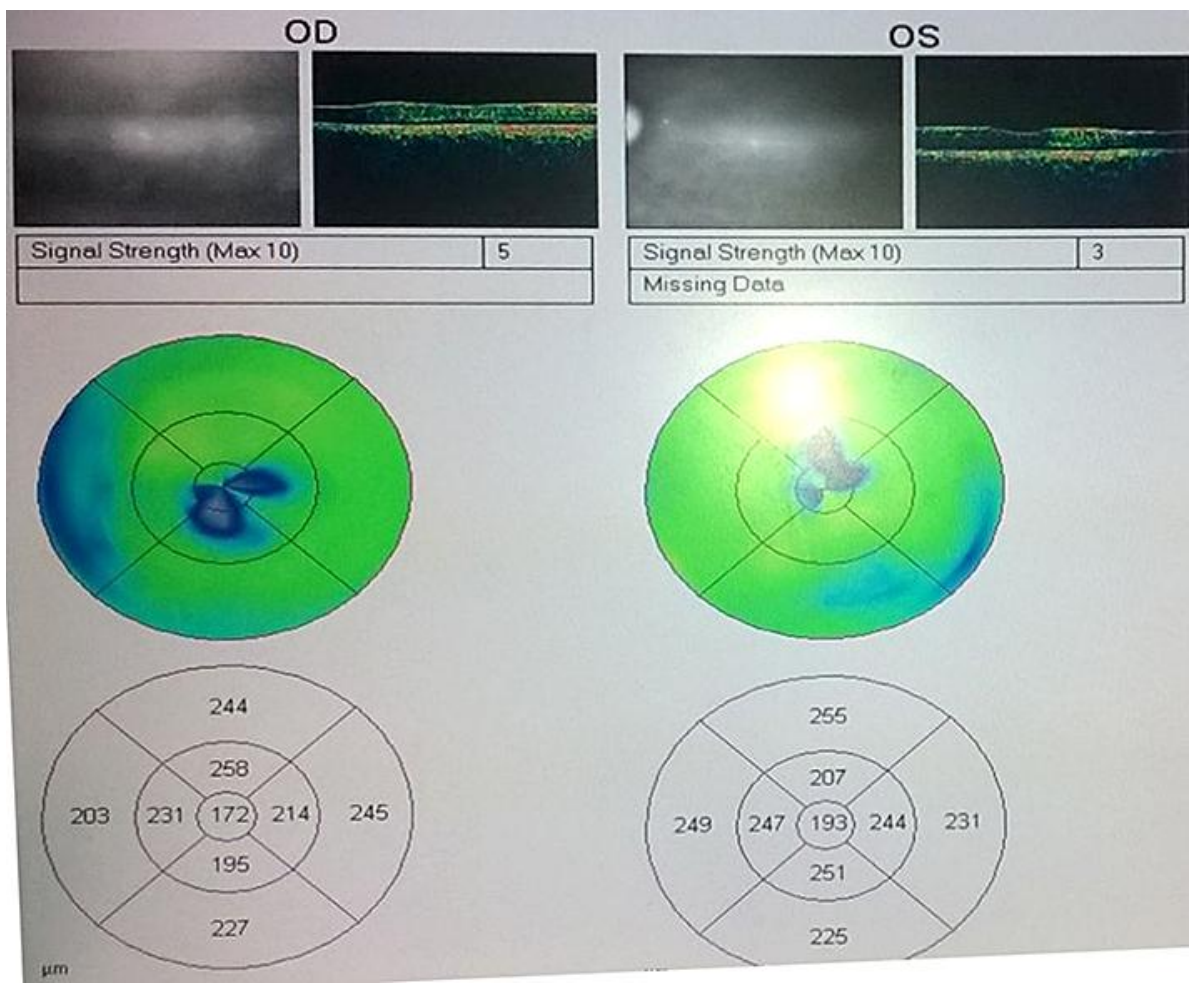

Fig. 5. Optical coherence tomography showing foveal atrophy. 